\title{
What are the therapeutic alternatives to dextropropoxyphene in France? A prescribers' survey
}

F.Aubrun $^{\mathrm{a}}$ E.Chrétien $^{\mathrm{a}}$ L.Letrilliart $^{\mathrm{b}}$ M.Ginoux ${ }^{\mathrm{c}}$ M.Belhassen $^{\mathrm{c}}$ M.Lanteri-Minet ${ }^{\mathrm{d}}$ E.Van Ganse $^{\mathrm{ce}}$ H.Beloeil ${ }^{\mathrm{f}}$

And Sfar members of pain-ALR committee

${ }^{a}$ Department of Anesthesiology and Critical Care, Université Claude-Bernard-Lyon 1, hospices civils de Lyon, CHU de Lyon, groupe hospitalier Nord-hôpital de la Croix-Rousse, 103, grande rue de la Croix-Rousse, 69317 Lyon cedex 04, France

${ }^{\mathrm{b}}$ Université Claude-Bernard-Lyon 1, collège universitaire de médecine générale, 8, avenue Rockefeller, 69373 Lyon cedex 08, France

c Université Claude-Bernard-Lyon 1, UMR CNRS 5558, faculté d’odontologie, 11, rue Guillaume-Paradin, 69372 Lyon cedex 08, France

d Department of Pain Management, université Nice-Sophia-Antipolis, Inserm/UdA, U1107, Neuro-Dol, université d'Auvergne, pôle neurosciences cliniques, CHU de Nice, hôpital de Cimiez, 4, avenue Reine-Victoria, 06000 Nice, France

e Hospices civils de Lyon, CHU de Lyon, groupe hospitalier Nord-hôpital de la CroixRousse, service de pneumologie, 103, grande rue de la Croix-Rousse, 69317 Lyon cedex 04, France

${ }^{\mathrm{f}}$ Université Rennes 1, CHU de Rennes, pôle d’anesthésie-Samu-urgences-réanimations, 2, rue Henri-Le-Guilloux, 35033 Rennes cedex 9, France 


\begin{abstract}
About a year after dextropropoxyphene (DXP) withdrawal from the French market, we conducted a survey among members of the French Society of Anesthesia \& Intensive Care Medicine (Sfar) and of the French Society of the Study and Treatment of Pain (SFETD) to identify the indications for which this WHO level II analgesic had been prescribed, the prescriber's feedback following withdrawal, and the substitutive analgesics prescribed. DXP had been prescribed by more than $75 \%$ of the 430 anaesthesiologists and 230 pain specialists interviewed, mainly for acute and chronic non-cancer pain of moderate intensity. While two thirds of pain specialists were not satisfied with DXP withdrawal, this decision did not affect the majority of anaesthesiologists. In both groups, the main substitutive analgesic was tramadol combined with acetaminophen, while only $24 \%$ of prescribers considered acetaminophen alone as a substitute.
\end{abstract}

\title{
Keywords : Pain; treatment, dextropropoxyphène.
}

\section{INTRODUCTION}

Dextropropoxyphene (DXP) has been one of the most widely prescribed and used analgesics in the world, specifically in France since the beginning of marketing in 1964 (more than 70 million packages sold per year) [1-3]. This drug was particularly prescribed in the elderly, as reported by a health and social welfare survey (ESPS) performed in 2000, showing that DiAntalvic ${ }^{\circledR}$ represented the largest drug item consumed by patients over 65 years old [4-6]. This opiate was indicated for the treatment of low to moderate intensity pain [3,7]. In France, more than thirty specialties contained DXP, most often in association with paracetamol (DXP/PC) [1,7].

Added to French Health Authorities' or Scientific Societies' (French Agency for Health Products Safety and French Academy of Medicine) [1] questions regarding the positivity of DXP benefit/risk ratio (this issue had been raised since 1998 by the French Society of Anesthesia and Intensive Care Medicine (Sfar) [8]), the occurrence of hundreds of deaths caused by drug poisoning and/or misuse in Northern Europe, Britain, United States and 
Australia, lead to the decision of progressively withdrawing DXP in North America and Australia, followed by Europe in June 2009, with a permanent cessation in France in March $2011[1,9-11]$.

Recommendations regarding therapeutic alternatives for DXP were produced by the National Agency for drugs and health products safety (the Afssaps, later renamed the ANSM) in collaboration with its general practitioners reference group, the French Society for the Study and Treatment of Pain (SFETD) and the French Society of Rheumatology (SFR) [12]. However, prescriber's concerns regarding the safety of these alternative analgesics, mainly tramadol, and regarding patient compliance with recommendations, may have affected DXP/PC substitution mechanisms, and subsequently the management of pain in France with impacts on public health.

To identify the therapeutic alternatives prescribed by anaesthesiologists and pain specialists after DXP withdrawal, a survey was conducted among Sfar and SFETD members. The second objective of the survey was to obtain physician feedback regarding the withdrawal of a popular drug in France, particularly as concerns the elderly.

\section{METHODOLOGY}

\section{Surveys of two Learned Societies involved in pain management}

A survey regarding DXP withdrawal targeted anaesthesiologist members of the French Society of Anaesthesia and Intensive Care Medicine active in secondary care (public and private hospitals), albeit not consulting for chronic pain. This survey (11 questions) was accessible on the www.sfar.org website (Appendix 1).

For SFETD members, a slightly different survey was provided to pain specialists active either in secondary care, or in centres for pain evaluation and treatment (CETD). This survey (15 questions) was available on the www.sfetd-douleur.org website (Appendix 2).

Survey Monkey ${ }^{\circledR}$ software was used to create the survey. Overall, 3000 SFARanaesthesiologists and 911 SFETD-pain specialists received a link to the surveys by mail. In the absence of reply after 2 months, two reminders were sent by email. Answers were anonymised before processing the data.

\section{Survey processing}


The two surveys were confidential and anonymous, and their final version was validated by the regional anaesthesia and pain committee and the administrative councils of both the SFAR and the SFETD. They were conducted between December 2012 and March 2013. SFAR and SFETD physicians were informed by email that a link was available to access a survey focused on DXP.

The survey questions assessed physician gender and age, work place and status, DXP prescribing uses before withdrawal, feedback regarding withdrawal and prescribing patterns after withdrawal. In addition to these questions, algologists had to provide detailed information on DXP prescribing before withdrawal (target populations, prescribing frequency, targeted pain intensity and indications).

\section{Data analysis}

Data were entered on EXCEL ${ }^{\circledR}$ sheets. Results were descriptive and presented as percentages. When applicable (comparison of results from different lines of activity), a $\chi^{2}$ test was applied. The significance threshold was set to $5 \%$. All analyses were performed using STATVIEW® software.

\section{RESULTS}

A total of 697 questionnaires were analysed, comprising 433 SFAR and 234 SFETD questionnaires. The Sfar and SFETD participation rates were $14.3 \%$ and $25.7 \%$, respectively. The general characteristics of surveyed physicians are presented in Table I.

\section{DXP prescribing uses before withdrawal: population? Types of pain?}

Before withdrawal, DXP was prescribed by $72.7 \%$ of anaesthesiologists and $80.6 \%$ of pain specialists. Both specialties prescribed this drug for pain of moderate intensity (Figure 1). However, 44.4\% anaesthesiologists also prescribed DXP for postoperative pain of low intensity. Two thirds of anaesthesiologists (68.6\%) prescribed this drug for outpatient surgery, $39.4 \%$ for patients suffering from painful medical conditions and $41.9 \%$ used this level II analgesic as a relay to level III analgesia.

Acute pain, chronic non-cancer pain and cancer pain represented $84.2 \%, 79.2 \%$ and $42.1 \%$ of DXP prescriptions by pains specialists, respectively. Among surveyed physicians, 31.7\% prescribed DXP occasionally, $49.2 \%$ frequently and $19.1 \%$ very frequently. The pain types 
leading to DXP prescribing are presented in Table 2, with a predominance of articular, lumbar and traumatic pain, rather than neuropathic and psychogenic pain.

\section{Reasons for not prescribing DXP before its withdrawal and feedback regarding its withdrawal}

Among 26.1\% of anaesthesiologists who did not prescribe DXP before withdrawal, 55.7\% used another drug and 27.4\% considered DXP unsafe (Table 3). Among 18.9\% of pain specialists who did not prescribe DXP before withdrawal, 42.9\% considered DXP unsafe and 33.3\% refused to prescribe it. DXP withdrawal affected prescriber's habits, with 33.3\% of anaesthesiologists and $57 \%$ of pain specialists dissatisfied of withdrawal. However, withdrawal did not affect the habits of $31.4 \%$ of anaesthesiologists and $24.4 \%$ of pain specialists, and it was welcomed by $35.3 \%$ of anaesthesiologists and $18.6 \%$ of pain specialists.

\section{DXP replacement procedures}

Physicians were surveyed about their personal DXP alternative strategies, if applicable. In most instances, SFAR and SFETD physicians favoured tramadol associated with paracetamol (77.8\% and 80.9\%, respectively (Figure 2). Most physicians were aware of ANSM (Afssaps) recommendations (60.5\% of anaesthesiologists and $84.5 \%$ of pain specialists). However, only $58.6 \%$ of anaesthesiologists used them to manage DXP withdrawal. The reasons for not following recommendations were either disagreement (108 AN, 19.6\%) or perception of insufficient clarity (12.6\%). Among pain specialists, $48.9 \%$ followed ANSM recommendations, while $20.4 \%$ disagreed and $16.7 \%$ perceived recommendations to be unclear.

\section{DISCUSSION}

DXP was withdrawn from the French market in 2011 after an initial EMA decision (European Medicines Agency), based on increased mortality mainly due to drug misuse [9,12-14]. This much prescribed and popular drug in France (in 2006, DXP was the second most reimbursed drug) was withdrawn from the French market despite remaining doubts on possible misuse in the country [15-16]. Nonetheless, a safety review has shown a high rate of serious Adverse Events associated with DXP/PC, more specifically liver impairments [17].

This survey was the first to evaluate the opinion of two pain specialist populations regarding DXP withdrawal and its consequences in terms of therapeutic alternatives. 
More than $75 \%$ of the 430 physicians surveyed prescribed DXP before its withdrawal, mainly to treat acute and non-cancer chronic pain of moderate intensity. Few differences were observed between the two populations surveyed. Almost all prescribers declared to have used DXP according to the PDR's indications, mostly related to joint conditions or traumatology. According to prescribing data collected in 2006 by DOREMA surveys (Documentation and marketing research), the DXP-PC combination was then mainly prescribed to treat lumbago and arthrosis. The mean posology was 4.6 tablets per day for a mean treatment duration of 30.8 days [18].

While almost two thirds of pain specialists felt concerned by the DXP withdrawal, this event did not have a significant impact on anaesthesiologists' habits. In both groups, the main substitution analgesic was tramadol associated with paracetamol, while paracetamol alone was used in $24 \%$ of cases. Hawton et al. [19] analysed the consequences in terms of morbidity or mortality and substitution, 6 years following DXP-PC withdrawal in Britain. Prescriptions of tramadol and paracetamol increased by $19 \%$ and $16 \%$ respectively, mainly in favour of a codeine-paracetamol association (+23\%). By contrast, in France, in an Academic Hospital, a study performed before the national DXP withdrawal showed that DXP withdrawal induced a $4.6 \%$ decrease in total analgesic consumption with a specific $28 \%$ reduction of level II drugs (increase of tramadol and decrease of the codeine-paracetamol association). During the same period, non-morphine analgesics showed an $11 \%$ increase, while consumption of morphine and related compounds decreased by $8 \%$ [15]. Due to the strong support from local teams involved in analgesia, the consequences of withdrawal were nonetheless different than those observed at the national or European scales [15,19]. Regarding the effects of DXP withdrawal on the effectiveness of pain management, Becquemont and al. analysed the consequences of withdrawal on elderly patients suffering from chronic pain. While tramadol (mainly), paracetamol, codeine and opium were the main therapeutic alternatives in this study, no consequence in terms of pain intensity, comfort or quality of life was found [20].

In our survey, most anaesthesiologists expressed satisfaction regarding the effects of DXP. They did not consider DXP to be dangerous nor ineffective. Nonetheless, the majority of health care professionals who did not prescribe DXP explained their attitude by pointing out the dangerousness and lack of efficacy of DXP. It is then paradoxical that the withdrawal was more accepted by anaesthesiologists than by pain specialists, the majority of whom did not follow the ANSM's recommendations. Nevertheless, the benefit/risk ratio was evaluated by DXP non-prescribers while withdrawal feedback was estimated by the whole group of physicians surveyed. 
In terms of replacement therapy, the Afssaps (ANSM) recommended tramadol/paracetamol and codeine/paracetamol, and to a lesser extent, paracetamol alone. While this switch was observed for pain specialists, it was independent of AFSSAPS recommendations that both groups largely ignored. It would then be of interest to investigate the determinants of physician's choice of replacement therapy, as there was no major difference between the groups regarding the distribution of alternative choices. Only the opium-paracetamol combination (Lamaline ${ }^{\circledR}$ ) was more prescribed by pain specialists than by anaesthesiologists, where the prescription rate was only $6 \%$.

This study has certain limitations. A declarative survey was used, and the quality of the information reported by the interviewed prescribers was not validated. Therefore, the data collected cannot be controlled. Moreover, the participation rate was low and the results may not be representative of the opinion of all anaesthesiologists and pain specialists at the national level. Finally, this study did not collect information on the consequences of substitution therapy in terms of substitutive drugs; it did not detail prescribed doses and patterns of use, nor compliance with marketing authorization.

In summary, 18 months following the DXP-paracetamol withdrawal, a survey was conducted among two prescriber populations: anaesthesiologists (SFAR) and pain specialists (SFETD). The survey confirmed the important place occupied by this drug, mainly prescribed for moderate pain, particularly in outpatient surgery and for articular pain. Substitutive analgesics were represented by tramadol, mainly associated with paracetamol, but also by codeineparacetamol, while paracetamol alone represented only $24 \%$ of all prescriptions. A specific analysis of national NHS claims data would be of major interest to confirm the substitutive strategies declared by surveyed physicians, and to follow a cohort of patients who used DXPparacetamol for several years in order to identify substitutive analgesics and their effects. Indeed, France was the major DXP-paracetamol user in Europe with almost 8 million consumers. It would be highly relevant to track such patients and to evaluate the clinical and economic consequences of DXP withdrawal, notably in terms of morbidity linked to substitute analgesics consumption.

\section{Thanks to}


We would like to thank the members of the Sfar ALR pain committee, the Sfar administration council for providing authorization and access to the SFAR database, and the SFETD administration council for providing authorization and access to the SFETD database.

Conflicts of interest: none.

\section{Bibliography}

1- ANSM. Agence Nationale de Sécurité du Médicament et des produits de santé. Médicaments contenant l'association dextropropoxyphène paracétamol. Recommandation de l'EMEA de retrait de ces médicaments à la suite de l'évaluation européenne et avis divergent de l'AFSSAPS. Juin 2009. www.ansm.sante.fr.

2- Barkin RL. Propoxyphene (dextropropoxyphene): a critical review of a weak opioid analgesic that should remain in antiquity. Am J Ther 2006; 13: 534-42.

3- Collins SL, Edwards JE, Moore RA, McQuay HJ. Single dose dextropropoxyphene, alone and with paracetamol (acetaminophen), for postoperative pain. Cochrane Database Syst Rev 2000; CD001440.

4- HAS. Haute Autorité de Santé. Consommation médicamenteuse chez le sujet agé. consommation, prescription, iatrogénie et observance. $\operatorname{Pr}$ S Legrain. 2005. www.has.sante.fr

5- Bertin P, Becquemont L, Corruble E, Derumeaux G, Falissart B, Hanon O, Pinget M, Forette $\mathrm{F}$. The therapeutic management of chronic pain in ambulatory care patients aged 65 and over in France: the S.AGES cohort. Baseline data. J Nutr Health Aging 201; 17: 681-6.

6- Goldstein DJ, Turk DC. Dextropropoxyphene : safety and efficacy in older patients. Drugs Aging 2005 ; 22 : 419-32.

7- VIDAL. Informations issues de l'Autorisation de mise sur le marché (AMM). Résumé des caractéristiques du produit (RCP). www.vidal.fr

8- Société française d'anesthésie et de réanimation. Conférence de Consensus. Prise en charge de la Douleur postopératoire chez l'adulte et l'enfant (1997). Ann Fr Anesth Réanim 1998; 17: 444-662, fi117-22. www.sfar.org

9- Food and Drug administration Public Health Service US department of Health And Human services. Food and Drug Administration recommends against the continues use of dextropropxyphene. J Pain Palliat Care Pharmacother 2011; 25 : 80-2.

10-Traynor K. Close vote by FDA advisers favors propoxyphene withdrawal. Am J Health Syst Pharm. 2009; 66 : 518-20.

11-ANSM. Agence nationale de sécurité du médicament et des produits de santé. Spécialités contenant du dextropropoxyphène : retrait du marché le 1er mars 2011. 16 février 2011. www.ansm.sante.fr

12-ANSM. Agence nationale de sécurité du médicament et des produits de santé. Prise en charge des douleurs de l'adulte modérées à intenses. Mise au point. 5 août 2011. www.ansm.sante.fr

13-Ray WA, Murray KT, Kawai V et al. Propoxyphene and the risk of out-of-hospital death. Pharmacoepidemiology Drug Safety 2013 ; 22 : 403-12

14-Handley SA, Flanagan RJ. Drugs and other chemicals involved in fatal poisoning in England and Wales during 2000-2011; Clin Toxicol 2014; 52 : 1-12. 
15-Gaubert S, Vie M, Damase-Michel C et al. Dextropropoxyphene withdrawal from a French university hospital: impact on analgesic drug consumption. Fund Clin Pharmacol 2009; 23 : 247-52.

16-CNAM. Caisse nationale d'assurance Maladie. "Medic'Am 2006". www.ameli.fr.

17-Tavassoli N, Lapeyre-Mestre M, Sommet A et al. Reporting rate of adverse drug reactions to the French pharmacovigilance system with three step 2 analgesic drugs: dextropropoxyphene, tramadol and codeine (in combination with paracetamol). BJCP 2009 ; $68: 422-6$.

18-HAS. Haute Autorité de Santé. Commission de transparence "avis Di-Antalvic» gélule. 25 avril 2007. www.has.sante.fr

19-Haxton K, Bergen H, Simkin S et al. Six-year follow-up of impact of co-proxamol withdrawal in England and Wales on prescribing and deaths: time-series study. Plos Med 2012 ; 9 : e1001213.

20-Becquemont L, Delespierre T, Bauduceau B et al. Consequences of dextropropoxyphene market withdrawal in elderly patients with chronic pain. Eur J Clin Pharmacol 2014 ; 70 : 1237-42. 
Table 1: Characteristics of physicians responding to the survey. CHU: University Hospital, CH : Public Hospital, CP : Private hospital. SFETD specialists (pain specialists) were allowed to validate several working places due to CETD (Centre for Evaluation and Treatment of Pain) geographic integration in different types of institutions. Age: number of responses: 432 for the Sfar and 234 for SFETD. Working place / status: number of responses: 432/432 for the Sfar and 231/228 for the SFETD. Certain SFETD physicians declared several functions.

Table 2: Pain subtypes leading to DXP prescription for Pain Specialists

Table 3: Question targeting physicians who were not prescribing DXP (q5: Before its withdrawal, did you prescribe DXP?). 113 (26\%) SFAR physicians and 43 (18.9\%) SFETD physicians were not prescribing DXP before its withdrawal.

Figure 1: Pain intensity (percentages) requiring DXP prescription before its withdrawal (VAS between 0: "no pain" and 10: "worst possible pain ") Weak pain (VAS < 3), moderate pain $(3<$ VAS $<6)$, severe pain (VAS $>6)$. Several possible answers.

Figure 2: Alternative drugs prescribed by Anaesthesiologists (A) and Pain specialists (B).

Tramadol PC: tramadol + Paracetamol; Codeine PC: codeine + Paracetamol; PC alone: Paracetamol alone. 
Appendix 1:

\section{Dextropropoxyphene (DXP) survey Intended for SFAR Anaesthesiologists Partners: SFAR/SFETD}

Forty years after the dextropropoxyphene-paracetamol association (DXP-PC, mainly represented by DiAntalvic () ) was made available on the hexagonal market, this association was withdrawn from part of the European market - and the French market in March 2011 - because of deaths due to intentional or accidental intoxications leading notably to respiratory depression, heart conduction disorders and renal failure in the elderly. Prescribers have been encouraged to reconsider medical care for their patients treated with this association by suggesting analgesic alternatives. This change was obviously difficult as France was the top European consumer with 8 million DXP users and more than 70 million units sold per year.

In 1997 and more recently in 2008, the SFAR expressed doubts regarding DXP's clinical efficacy in postoperative analgesia. However, this drug was not only used in a perioperative context, as evidenced by considering the very high number of DXP-PC users in our country. As a reminder: in 2006, DXP was the second-highest prescribed drug reimbursed by the general health insurance regime.

The main goal of this survey was to determine and identify the therapeutic alternatives prescribed, particularly by anaesthesiologists. Indeed, it is of high relevance to know whether prescribers have chosen to substitute DXP by an analgesic of similar level, increased or decreased their prescribing levels, or suppressed the treatment without replacement. Never before has such a highly prescribed drug been suppressed from the French pharmacopeia.

The secondary objective was to evaluate physician feedback regarding this withdrawal. It should also imply knowledge of the drug prescription pattern before withdrawal. 


\section{Investigation on Dextropropoxyphene (DXP) withdrawal \\ Hospital centres and clinics}

To anaesthesiologists who do not practice chronic pain consultations

11 questions ( $<5$ minutes)

v6 November 2012

Stratification was performed on institution's type (university, public non university, private) and size (number of interventions with surgical stays). We thus obtained five strata: university hospital centres ( $\mathrm{CHU}$ ), large (> 2700 interventions per year) public hospital centres $(\mathrm{CH})$, small $\mathrm{CH}$; large (> 3200 interventions per year) private centres (CP) and small CP.

Q1: who are you?

1- a man

2- a woman

Q2: how old are you?

Q3: where do you work? (only one answer is possible)

1- Teaching hospital

2- Large Public hospital

3- Small Public Hospital

4- Large private centre

5- Small private centre

Q4: what is your status? (only one answer is possible)

1- Hospital Practitioner

2- Academic Assistant

3- Hospital assistant

4- Private physician

5- University professor

6- Residents

Q5: Before its withdrawal, were you prescribing DXP? (only one answer is possible)

1- Yes

2- No

3- Do not know

Q5a: If yes, for which indications? (several possible answers)

1- Prescriptions for surgical postoperative pain of low intensity (VAS $\leq 3 / 10$ )

2- Prescriptions for surgical postoperative pain of moderate intensity (VAS between 3 and 6/10)

3- Prescriptions for surgical postoperative pain of severe intensity (VAS > 6/10)

3- Postoperative prescriptions in outpatient surgery

4- Medical indications (for example headaches)

5- Switch to a level III analgesic (opioid and non-opioid)

6- Others

Q5b: If no, for what reasons? (several possible answers)

1-You never wanted to prescribe this drug in the past

Why?

2- You anticipated the withdrawal of this dangerous drug 
3- You anticipated the withdrawal of this ineffective drug

4- Your hospital pharmacy was not dispensing this drug anymore

5- You never had access to this medication

6- You used to prescribe another drug

7- You used it in the past but one of your patients displayed adverse events justifying its discontinuation

Which adverse event(s)

8- No opinion

Q6: How did you react after DXP withdrawal? (only one answer is possible)

1- The withdrawal disturbed your habits and you were not satisfied

2- The withdrawal did not change your habits

3- You had to modify your habits and it was a positive event

Q7: Upon withdrawal, what has been your choice for replacing this drug? (several answers possible)

1- You are prescribing tramadol alone

2- You are prescribing tramadol associated with paracetamol

3- You are prescribing codeine associated with paracetamol

4- You are prescribing lamaline (Opium)

5- You are prescribing morphine alone

6- You are prescribing another opioid drug, which one?

7- You are prescribing paracetamol alone

8- You are prescribing another non-opioid drug, which one?

9- Do not know

Q8: Are you aware of AFSSAPS (ANSM) recommendations regarding this drug withdrawal? (only one answer is possible)

1- Yes

2- No

Q8a: If yes, did you take them in account when managing DXP replacement for your patients?

1- Yes

2- No, they are not clear

3- No, you disagree with these recommendations

4- Other reason

THANK YOU 


\section{Enquête Dextropropoxyphène (DXP) \\ Intended for SFETD Physicians Partners: SFAR/SFETD}

Forty years after the dextropropoxyphene-paracetamol association (DXP-PC, mainly represented by DiAntalvic $($ ) was made available on the hexagonal market, this association was withdrawn from part of the European market - the French market in March 2011 - because of deaths due to intentional or accidental intoxications leading notably to respiratory depression, heart conduction disorders and renal failure in the elderly. While the European Medicines Agency (EMA) identified 200 to 300 deaths per year in Sweden and in England, there were about 65 deaths per year in France attributable to DXP; for the AFSSAPS and the Medicine academy, this relatively low number was due to to less misuse, different packaging and different delivery processes in France.

Prescribers have been encouraged to reconsider medical care for their patients treated with this association by suggesting analgesic alternatives. To do so, an algorithm has been proposed since 2010 collectively by the AFSSAPS, the general practitioners reference group of this agency, the French society of pain study and treatment (SFETD) and the French society of rheumatology (SFR). Depending on pain subtype (acute or chronic) and intensity (low to severe), this decision tree helps indicate therapeutic alternatives, with the administration of paracetamol or AINS alone, prescription of a level II analgesic, or introduction of a level III analgesic.

This change was nonetheless obviously difficult, as France was the top European consumer with 8 million DXP users and more than 70 million units sold per year. In 1997 and more recently in 2008, the SFAR expressed doubts regarding DXP's clinical efficacy in postoperative analgesia. However, this drug was not restricted to a perioperative context in view of the very high number of DXP-PC users in our country. As a reminder, in 2006, DXP was the second-most prescribed drug reimbursed by the general health insurance regime.

Besides the risk of overdose, it is necessary to highlight the fact that a sudden discontinuation of a chronic treatment DXP could lead, as for any morphinic-like drug, to a withdrawal syndrome with very serious consequences. The procedure for DXP substitution by another drug, or for drug discontinuation, had therefore to be applied very carefully, according to December 2010 recommendations, even if these recommendations were very theoretical.

The main goal of this survey is to determine and identify the therapeutic alternatives prescribed by the three specialties most involved in acute and chronic pain management, particularly by dedicated pain physicians. Indeed, it is of high relevance to known whether prescribers have chosen to substitute DXP by an analgesic of similar level, increased or decreased their prescription level, or suppressed the treatment without replacement. Never before has such a highly prescribed drug been suppressed from the French pharmacopeia.

The secondary objective was to evaluate physician feedback regarding this withdrawal. It should also imply knowledge of the drug prescription pattern before its withdrawal. 


\section{Investigation on the 2011 Dextropropoxyphene (DXP) withdrawal Hospital centres, clinics, CETD, private doctors}

To dedicated pain physicians:

The practitioners will be surveyed through the SFETD network

15 questions ( $<5$ minutes)

6 November 2012

2- Q1: Who are you?

1- a man

2- a woman

Q2: how old are you?

Q3: where do you work? (only one answer is possible)

1- Teaching hospital

2- Large Public hospital

3- Small Public Hospital

4- Large private centre

5- Small private centre

6- CETD (centre for pain evaluation and treatment)

7- Private practice in an office

Q4: what is your status? (only one answer is possible)

1- Hospital Practitioner

2- Academic Assistant

3- Hospital assistant

4- Private doctor

5- University professor

6- Resident

Q5: Before its withdrawal, were you prescribing DXP? (only one answer is possible)

1-Yes

2- No

3- Do not know

Q5a: If yes, for which population?

Age : (several possible answers)

1- Prescriptions for children

2- Prescriptions for young patients

3- Prescriptions for the elderly (> 65 years old)

4- Any age

Q5b: If yes, at what frequency?

Frequency: (only one answer is possible) 
1- Occasional prescriptions

2- Frequent prescriptions

3- Very frequent

Q5c: If yes, for what type of pain intensity? (several possible answers)

1- Pain of low intensity

2- Pain of moderate intensity

3- Pain of severe intensity

Q5d: If yes, for what indications? (several possible answers)

1- $\quad$ Acute pain

2- $\quad$ Chronic non-cancer pain

3- Chronic cancer pain

Q5e: If yes, mainly for some pain subtypes (provide the 3 most frequent)

1- Dental pain

2- Headache and trigeminal cephalalgia

3- ENT pain

4- Lumbar pain

5- Articular pain

6- Traumatic pain

7- Central neuropathic pain (for example post-stroke)

8- Peripheral neuropathic pain (for example diabetes)

9- Abdominal pain

10- Pelvic or perineal pain

11- Cancer pain

12- AIDS pain

13- Pain related to medical care or proceedings

14- Psychogenic pain

15- Others

Q5f: If No, for what reasons? (several possible answers)

1- You never wanted to prescribe this drug in the past

Why?

2- You anticipated the withdrawal of this dangerous drug

3- You anticipated the withdrawal of this ineffective drug

4- Your hospital pharmacy was not dispensing this drug anymore

5- You never had access to this medication

6- You used to prescribe another drug

7- You used it in the past but one of your patients displayed adverse events justifying its discontinuation

Which adverse event(s)

8- No opinion

Q6: How did react after DXP withdrawal? (only one answer is possible)

1- The withdrawal disturbed your habits and you are not satisfied

2- The withdrawal did not change your habits

3- You had to modify your habits and is was a positive event

Q7: Upon withdrawal, what has been your choice to replace this drug? (several answers possible)

1- You are prescribing tramadol alone

2- You are prescribing tramadol associated with paracetamol 
3- You are prescribing codeine associated with paracetamol

4- You are prescribing lamaline (opium)

5- You are prescribing morphine alone

6- You are prescribing another opioid drug, which one?

7- You are prescribing paracetamol alone

8- You are prescribing another non-opioid drug, which one?

9- Do not know

Q8: Are you aware of AFSSAPS (ANSM) recommendations regarding this drug withdrawal? (only one answer is possible)

1- Yes

2- No

Q8a: If yes, did you take them in account when managing DXP replacement for your patients?

1- Yes

2- No, they are not clear

3- No, you disagree with these recommendations

4- Other reason

THANK YOU 


\begin{tabular}{|c|c|c|c|}
\hline & & SFAR $(n=433)$ & SFETD $(n=234)$ \\
\hline Gender & Men/Women : n (\%) & $\begin{array}{c}288 / 145 \\
(66,5 / 33,5)\end{array}$ & $\begin{array}{c}127 / 107 \\
(54,3 / 45,7)\end{array}$ \\
\hline Age & Mean $( \pm S D)$ & $48,1( \pm \mathbf{1 1}, \mathbf{4})$ & $51,5( \pm \mathbf{9 , 6 )}$ \\
\hline \multirow[t]{8}{*}{ Working place } & CHU: n (\%) & $177(40,9)$ & $75(32,1)$ \\
\hline & Large CH: n (\%) & $75(17,3)$ & $55(23,5)$ \\
\hline & Small CH: n (\%) & $23(5,3)$ & $32(13,7)$ \\
\hline & Large CP: n (\%) & $91(21,0)$ & $30(12,8)$ \\
\hline & Small CP: n (\%) & $66(15,2)$ & $20(8,5)$ \\
\hline & CETD: n (\%) & $0(0)$ & $54(23,1)$ \\
\hline & Liberal practice: n (\%) & $0(0)$ & $30(12,8)$ \\
\hline & No answer & $1(0,2)$ & $3(1,3)$ \\
\hline \multirow[t]{6}{*}{ Status } & Senior physician & $207(47,8)$ & $136(58,1)$ \\
\hline & Private doctors & $128(29,6)$ & $61(26,1)$ \\
\hline & Assistant & $39(9,0)$ & $20(8,5)$ \\
\hline & Resident & $33(7,6)$ & $10(4,3)$ \\
\hline & Academic physician & $25(5,8)$ & $18(7,7)$ \\
\hline & No answer & $1(0,2)$ & $6(2,6)$ \\
\hline
\end{tabular}




\begin{tabular}{|c|c|}
\hline Pain subtypes & $\%$ \\
\hline Articular & 76,1 \\
\hline Lumbar & 73,3 \\
\hline Traumatic & 55,6 \\
\hline Dental & 24,4 \\
\hline Cancer & 22,2 \\
\hline Headache and acute trigeminal \\
cephalalgia & 10 \\
\hline Related to medical care or proceedings & 8,9 \\
\hline ENT & 7,8 \\
\hline Abdominal & 6,1 \\
\hline Pelvic or perineal & 6,1 \\
\hline Other & 4,4 \\
\hline Peripheric neuropathic (ex : diabetes) & 3,9 \\
\hline Psychogenic & 0,6 \\
\hline AlDS & 0,6 \\
\hline Central neuropathic (post stroke) & 0 \\
\hline
\end{tabular}




\begin{tabular}{|l|c|c|}
\hline N (\%) & $\begin{array}{c}\text { Anesthesiologists } \\
\text { (n =113/433) }\end{array}$ & $\begin{array}{c}\text { Pain specialists } \\
\text { (n=42/234) }\end{array}$ \\
\hline You never wanted to prescribe DXP in the past & $19(16.8)$ & $14(33.3)$ \\
\hline $\begin{array}{l}\text { You anticipated the withdrawal of this dangerous } \\
\text { drug }\end{array}$ & $31(27.4)$ & $\mathbf{1 8}(\mathbf{4 2 . 9 )}$ \\
\hline $\begin{array}{l}\text { You anticipated the withdrawal of this ineffective } \\
\text { drug }\end{array}$ & $21(18.6)$ & $13(31)$ \\
\hline $\begin{array}{l}\text { Your hospital pharmacy was not dispensing this } \\
\text { drug anymore }\end{array}$ & $5(4.4)$ & $2(4.8)$ \\
\hline Your healthcare facility never provided this drug & $8(7.1)$ & $2(4.8)$ \\
\hline $\begin{array}{l}\text { You never prescribed DXP because you used to } \\
\text { prescribe another drug }\end{array}$ & $\mathbf{6 3 ( 5 5 . 7 )}$ & $0(21.4)$ \\
\hline $\begin{array}{l}\text { You used DXP in the past but one of your patient } \\
\text { had an adverse event justifying its discontinuation }\end{array}$ & $4(3.5)$ & $1(2.4)$ \\
\hline \begin{tabular}{l} 
No opinion \\
\hline
\end{tabular} & $3(2.6)$ & $0)$ \\
\hline
\end{tabular}




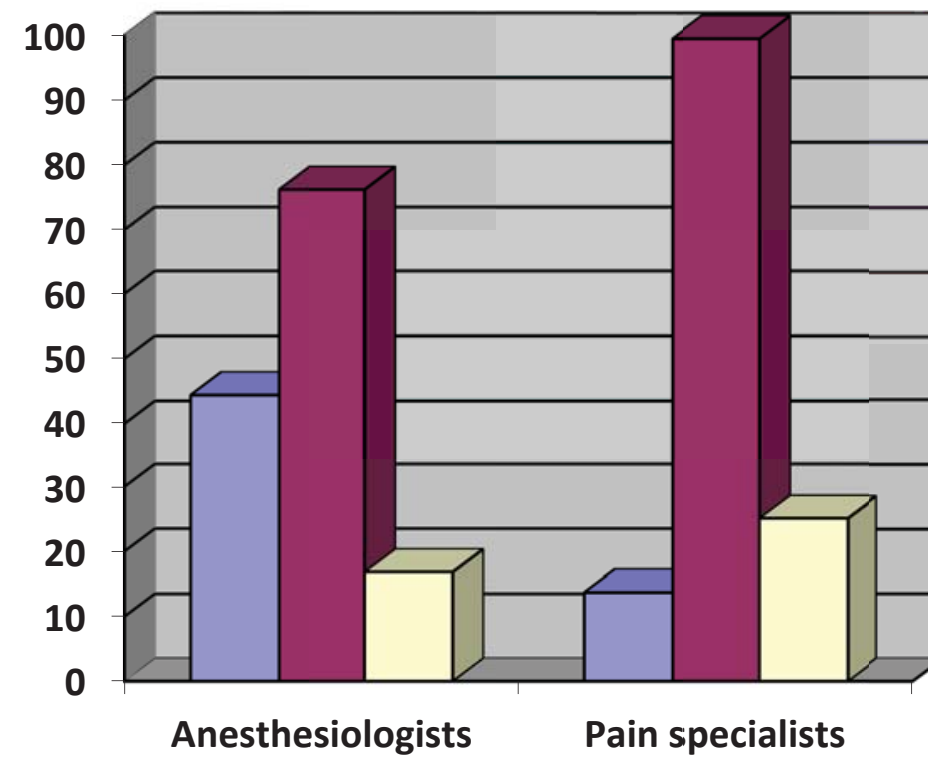

$\square$ Weak
$\square$ moderate
$\square$ Severe

$\square$ Severe 


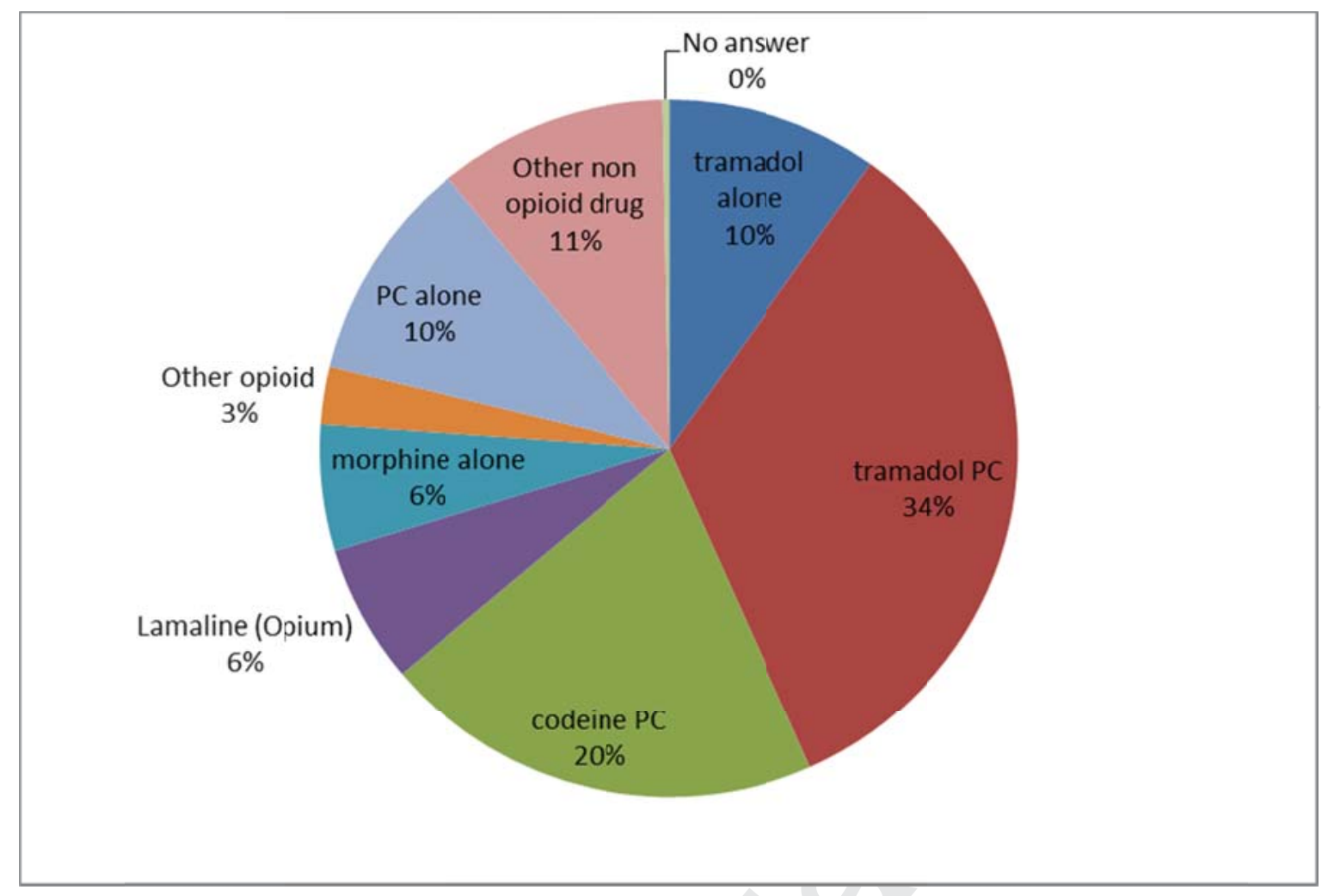

Page 22 of 23 


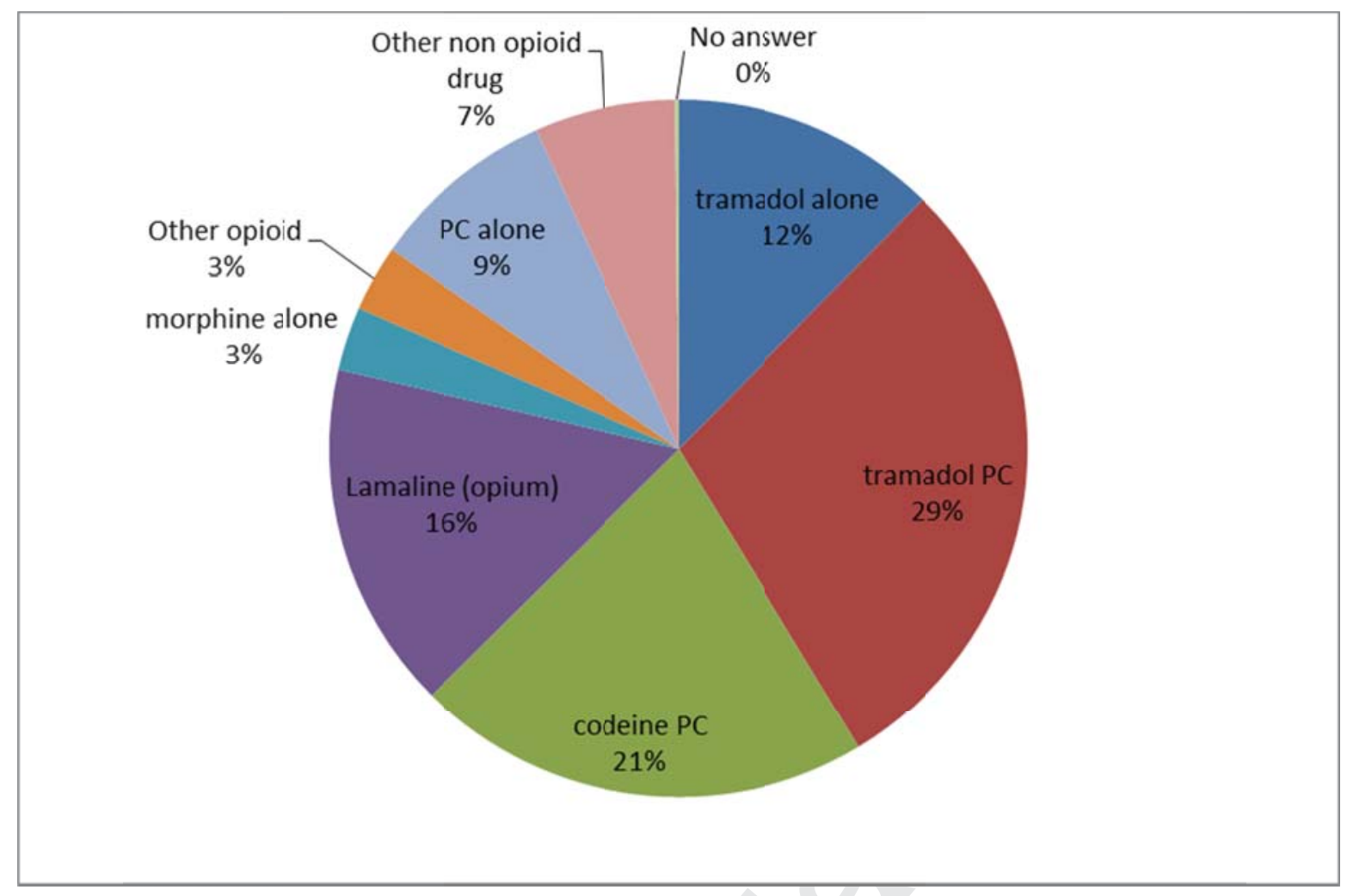

Page 23 of 23 